NASA/CR-2003-212586

\title{
Structure and Stability of One-Dimensional Detonations in Ethylene-Air Mixtures
}

S. Yungster and K. Radhakrishnan

Ohio Aerospace Institute, Brook Park, Ohio 
Since its founding, NASA has been dedicated to the advancement of aeronautics and space science. The NASA Scientific and Technical Information (STI) Program Office plays a key part in helping NASA maintain this important role.

The NASA STI Program Office is operated by Langley Research Center, the Lead Center for NASA's scientific and technical information. The NASA STI Program Office provides access to the NASA STI Database, the largest collection of aeronautical and space science STI in the world. The Program Office is also NASA's institutional mechanism for disseminating the results of its research and development activities. These results are published by NASA in the NASA STI Report Series, which includes the following report types:

- TECHNICAL PUBLICATION. Reports of completed research or a major significant phase of research that present the results of NASA programs and include extensive data or theoretical analysis. Includes compilations of significant scientific and technical data and information deemed to be of continuing reference value. NASA's counterpart of peerreviewed formal professional papers but has less stringent limitations on manuscript length and extent of graphic presentations.

- TECHNICAL MEMORANDUM. Scientific and technical findings that are preliminary or of specialized interest, e.g., quick release reports, working papers, and bibliographies that contain minimal annotation. Does not contain extensive analysis.

- CONTRACTOR REPORT. Scientific and technical findings by NASA-sponsored contractors and grantees.
- CONFERENCE PUBLICATION. Collected papers from scientific and technical conferences, symposia, seminars, or other meetings sponsored or cosponsored by NASA.

- SPECIAL PUBLICATION. Scientific, technical, or historical information from NASA programs, projects, and missions, often concerned with subjects having substantial public interest.

- TECHNICAL TRANSLATION. Englishlanguage translations of foreign scientific and technical material pertinent to NASA's mission.

Specialized services that complement the STI Program Office's diverse offerings include creating custom thesauri, building customized databases, organizing and publishing research results ... even providing videos.

For more information about the NASA STI Program Office, see the following:

- Access the NASA STI Program Home Page at http://www.sti.nasa.gov

- E-mail your question via the Internet to help@sti.nasa.gov

- Fax your question to the NASA Access Help Desk at 301-621-0134

- Telephone the NASA Access Help Desk at 301-621-0390

- Write to:

NASA Access Help Desk

NASA Center for AeroSpace Information 7121 Standard Drive

Hanover, MD 21076 
NASA/CR-2003-212586

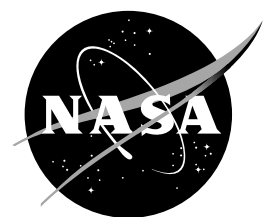

\section{Structure and Stability of One-Dimensional Detonations in Ethylene-Air Mixtures}

S. Yungster and K. Radhakrishnan

Ohio Aerospace Institute, Brook Park, Ohio

Prepared for the

33rd Fluid Dynamics Conference and Exhibit

sponsored by the American Institute of Aeronautics and Astronautics

Orlando, Florida, June 23-26, 2003

Prepared under Contract GSN 003049

National Aeronautics and

Space Administration

Glenn Research Center 
This work was sponsored by the Low Emissions Alternative Power Project of the Vehicle Systems Program at the NASA Glenn Research Center.

Available from

NASA Center for Aerospace Information 7121 Standard Drive

Hanover, MD 21076
National Technical Information Service 5285 Port Royal Road Springfield, VA 22100

Available electronically at http:/ /gltrs.grc.nasa.gov 


\title{
STRUCTURE AND STABILITY OF ONE-DIMENSIONAL DETONATIONS IN ETHYLENE-AIR MIXTURES
}

\author{
S. Yungster and K. Radhakrishnan \\ Ohio Aerospace Institute \\ Brook Park, Ohio 44142
}

\begin{abstract}
The propagation of one-dimensional detonations in ethylene-air mixtures is investigated numerically by solving the one-dimensional Euler equations with detailed finite-rate chemistry. The numerical method is based on a second-order spatially accurate total-variation-diminishing scheme and a point implicit, first-order-accurate, time marching algorithm. The ethylene-air combustion is modeled with a 20 -species, 36-step reaction mechanism. A multi-level, dynamically adaptive grid is utilized, in order to resolve the structure of the detonation. Parametric studies over an equivalence ratio range of $0.5 \leq \phi \leq 3$ for different initial pressures and degrees of detonation overdrive demonstrate that the detonation is unstable for low degrees of overdrive, but the dynamics of wave propagation varies with fuel-air equivalence ratio. For equivalence ratios less than approximately 1.2 the detonation exhibits a short-period oscillatory mode, characterized by high-frequency, low-amplitude waves. Richer mixtures $(\phi>1.2)$ exhibit a low-frequency mode that includes large fluctuations in the detonation wave speed; that is, a 'galloping' propagation mode is established. At high degrees of overdrive, stable detonation wave propagation is obtained. A modified McVey-Toong short-period wave-interaction theory is in excellent agreement with the numerical simulations.
\end{abstract}

\section{Introduction}

The basic structure of a detonation wave was determined independently by Zeldovich, von Neumann, and Doring (e.g., Williams ${ }^{1}$ ). The ZND model postulates that detonation waves have a steady, one-dimensional structure consisting of a lead shock wave followed by a reaction zone that is initiated by shock heating. The heat release in the chemically reactive material sustains the lead shock of the detonation wave. The minimum sustainable steady detonation speed occurs at the Chapman-Jouguet condition, for which the combustion products move at sonic speed relative to the lead shock. Detonation waves traveling at speeds higher than the Chapman-Jouguet velocity are called overdriven detonations.

Subsequent experimental and theoretical studies have shown that the ZND structure is unstable. The instabilities are responsible for the complex detonation systems observed in practice, ranging from cellular three-dimensional structures to one-dimensional pulsating and 'galloping' detonations. The objective of this paper is to study computationally the nonlinear development of pulsating instabilities in one-dimensional detonations.

Much of the previous computational research on the stability of one-dimensional gaseous detonations was based on the one-dimensional Euler equations for an ideal gas, with a one-step, irreversible chemical reaction governed by Arrhenius kinetics to model the combustion process. For example, Fickett \& Wood $^{2}$, Abouseif \& Toong ${ }^{3}$, and Bourlioux, Majda $\&$ Roytburd ${ }^{4}$ used this simplified model to study the stability of overdriven, piston-supported, one-dimensional detonations using different computational techniques. They used the steady, overdriven ZND detonation wave solution as initial conditions. Their results indicated that flow instabilities could produce various oscillation phenomena, ranging from highly uniform to chaotically irregular pulsating detonations. The study of Bourlioux $e t . a l^{4}$ showed in particular the need for sufficient grid resolution around the detonation front to avoid the appearance of nonphysical numerical artifacts. In addition, for highly overdriven detonations they obtained steady solutions with their simplified chemistry model.

These highly simplified chemistry models are convenient for mathematical analysis and algorithm development, but are of limited applicability. For example, one-step chemistry models cannot model the initiation, branching, and recombination steps characteristic of the combustion process at the detonation front and therefore cannot reproduce the interactions between the chemical kinetics and fluid dynamics. This coupling determines the dynamics of detonation wave propagation.

A few one-dimensional detonation wave studies have been conducted with more detailed chemistry models. Fickett, Jacobson \& $\operatorname{Schott}^{5}$ modeled the chain-branching mechanism with modified Arrhenius kinetics, but considered only one chemical reaction. Their model could be tuned to cover different values for the length of the induction and reaction zones. Their work showed that the structure of the pulsating detonations (i.e., the frequency of oscillation) is strongly affected by the use of a more realistic chemistry model. 
Short \& Quirk ${ }^{6}$ and Sanchez et. $a l^{7}$ have recently reported results using generic three-step global branched-chain chemistry models. Their studies were able to reproduce the essential dynamics of chain-branching reaction systems. Their results indicated that the ratio of the length of the chain-branching induction zone to the length of the recombination zone plays a major role in the structure and stability of detonation waves. However, the three-step reaction mechanisms used in these studies are not representative of any particular fuel-oxidant-diluent system.

Previous computational studies addressing the stability of one-dimensional gaseous detonations with a realistic chemistry model have been carried out by Sussman ${ }^{8}, \mathrm{He}^{9}$ and Yungster and Radhakrishnan ${ }^{10,11}$. Sussman used a detailed hydrogen-air combustion mechanism to investigate the oscillation characteristics of a stoichiometric hydrogen-air mixture for different degrees of detonation overdrive. His analysis started from the steady, overdriven ZND solution and calculated the transition to the oscillatory propagation mode. Sussman ${ }^{8}$ concluded that the longitudinal-oscillation mode depends on the ratio of the heat release time to the induction time. $\mathrm{He}^{9}$ investigated the direct initiation of detonations by an energy source using both a one-step reaction model and a detailed combustion mechanism for hydrogen-oxygen. Yungster and Radhakrishnan ${ }^{10,11}$ analyzed the structure and stability of one-dimensional hydrogen-air detonations for different mixture equivalence ratios, pressures and degrees of overdrive, using a detailed combustion mechanism. Their results showed that a modified McVey-Toong ${ }^{12}$ short-period wave-interaction theory that takes into account the finite heat-release time significantly improves agreement between theory and numerical simulations over the entire equivalence ratio and pressure ranges ${ }^{11}$.

On the experimental side, Lehr $^{13}$ examined the longitudinal oscillations in shock-induced combustion flows. His ballistic-range experiments consisted of spherical-nosed projectiles fired into premixed combustible mixtures. Depending on the experimental conditions, steady or unsteady flows were obtained. Two types of unsteady modes were observed: one consisting of very uniform, low-amplitude and high-frequency oscillations, and the other consisting of less regular, high-amplitude and low-frequency oscillations. The oscillations observed in these experiments are caused by the same longitudinal instabilities associated with the one-dimensional detonations considered here.

The objective of the present study is to extend our previous work ${ }^{10,11}$ on the analysis of the structure and stability of one-dimensional detonations by studying ethylene-air systems using a detailed combustion mechanism, for different mixture equivalence ratios, pressures and degrees of over- drive. The motivation for studying detonations in ethylene-air mixtures includes the increasing interest in developing pulse detonation engines (PDE) fueled by hydrocarbons. Ethylene is a gaseous fuel with one of the shortest ignition times among hydrocarbons, making it especially attractive for PDE application. In fact, several experimental studies on PDEs have utilized ethylene as fuel ${ }^{14,15}$. Moreover, ethylene is one of the most important intermediate species in pyrolysis and oxidation of higher hydrocarbons, including JP-10 ( $\mathrm{Li}$ et al. ${ }^{16}$ ). Finally, one-dimensional pulsating detonations have been observed in ballistic experiments for hydrogen-air mixture only. It is therefore important to determine whether these longitudinal instabilities are unique to hydrogen, or they are present in other fuels as well.

In this study, we consider a tube closed at one end and open at the other and compute the development of the detonation wave from its (direct) initiation to the final establishment of an oscillating propagation mode. The degree of overdrive is determined by the pressure in the driver gas, as described later. This approach is significantly different from that used in all previous studies ${ }^{11}$; in particular it eliminates the need for the steady-state ZND solution.

\section{Numerical Simulations}

The conservation form of the one-dimensional unsteady Euler equations for a chemically reacting gas mixture consisting of $n_{s}$ species can be written as

$$
\frac{\partial \boldsymbol{Q}}{\partial t}+\frac{\partial \boldsymbol{F}}{\partial x}=\boldsymbol{W}
$$

where

$$
\begin{gathered}
\boldsymbol{Q}=\left[\rho_{1}, \rho_{2}, \ldots, \rho_{n_{s}}, \rho u, e\right]^{T}, \\
\boldsymbol{F}=\left[\rho_{1} u, \rho_{2} u, \ldots, \rho_{n_{s}} u, \rho u^{2}+p, u(e+p)\right]^{T}, \\
\boldsymbol{W}=\left[w_{1}, w_{2}, \ldots, w_{n_{s}}, 0,0\right]^{T} .
\end{gathered}
$$

Here $\rho_{\mathrm{i}}$ is the density of the ith species, $\rho=\sum_{i=1}^{n_{s}} \rho_{i}$ the mixture density, $u$ the velocity, $p$ the pressure, and $e$ the total energy per unit volume. The terms $\left\{w_{i}\right\}$ represent the rates of production of species from chemical reactions.

The numerical method used for solving the governing equation set is based on Yee's second-order spatially accurate total-variation-diminishing (TVD) scheme ${ }^{17}$, and a point implicit, first-order, time-accurate marching algorithm. 
This method is a subset of a more general class of BDF methods considered by Yungster and Radhakrishnan ${ }^{18}$. A detailed description of the numerical method is given in ref. 11. Similar first-order, time-accurate point-implicit methods have been used by Sussman ${ }^{8}$, Wilson and $\operatorname{Sussman}^{19}$, and Matsuo and Fuji ${ }^{20}$ to study the longitudinal oscillations occurring in shock-induced combustion.

In order to maintain adequate numerical resolution of the detonation wave front, without the need to use hundreds of thousands of grid points, a multi-level, dynamically adaptive grid is utilized. Figure 1 shows a section of the grid at three different times as the detonation wave moves from left to right. The grid constantly adapts to keep the detonation front within the finest grid level. An arbitrary number of levels can be specified. Nine or ten grid levels were used in the present study, and 100 points were included in the finest grid level.

The ethylene-air combustion was modeled using the short chemical reaction mechanism of Li et al. ${ }^{16}$, which consists of 36 reactions among 20 species (see Table 1), with nitrogen being treated as an inert (i.e., non-reacting) species. This mechanism was designed to yield reasonably accurate results (ignition times differed from those of a more detailed mechanism by less than $30 \%$ ) over the range of post-shock temperatures between $1000 \mathrm{~K}$ and $2500 \mathrm{~K}$, pressures between 0.5 and 100 bar and equivalence ratios between 0.5 and 3. This combustion model was recently successfully used by Povinelli and Yungster ${ }^{21}$ to study the effects of dissociation and subsequent recombination on the performance of pulse detonation engines. In particular, the equilibrium Chapman-Jouguet detonation speed and von-Neumann state calculated with this mechanism agreed well with the results produced by the chemical equilibrium code $\mathrm{CEA}^{22}$.

\section{Results and Discussion}

There are two methods by which detonation can be formed in general: (1) by direct initiation, wherein a strong shock wave is generated in the tube (with a charge of solid explosive or by using a high pressure reservoir) and (2) by transition from a deflagration. In this paper, we consider development of detonations with direct initiation. Figure 2 shows a schematic of the initiation process. A high-pressure, high-temperature driver gas, consisting of nitrogen, was used in a small region next to the head-end of the tube. When the computation is started, a shock wave travels to the right and an expansion wave propagates to the left, towards the head-end. The shock wave is strong enough to initiate chemical reactions in the combustible mixture. Depending on the mixture properties, the shock wave and the combustion front subsequently merge and form a detonation wave. The value of the driver pressure, $p_{d r i v}$, will determine the degree of overdrive of the resulting detonation wave, $f$, defined as

$$
f=D^{2} / D_{C J}^{2}
$$

where $D$ is the actual detonation propagation speed and $D_{C J}$ is the theoretical Chapman-Jouguet detonation speed. (Since the flow behind an overdriven detonation is subsonic, this solution is susceptible to degradation by rarefaction waves from the closed end. With the overdriven detonation wave established, these rarefaction waves will eventually overtake the detonation front and reduce its speed towards the Chapman-Jouguet condition. All cases considered in this paper were computed for time intervals much shorter than those required to encounter this situation).

The first case considers a stoichiometric mixture of ethylene-air at $p_{0}=0.2$ bar and $T_{0}=298 \mathrm{~K}$ and a driver pressure ratio, $r_{p}=p_{\text {driv }} / p_{0}$, of 150 . A grid refinement study for this case is presented in figure 3 . Numerical results are presented for four successively refined grids having a minimum spacing, $\Delta x_{\text {min }}$, indicated in each figure. The plots show the variation in the detonation speed with time. The initiation process is similar to that of hydrogen-air mixtures, and is described in detail in Ref. 10.

It can be observed that the structure of the detonation wave changes with grid spacing. For the two coarsest grids (figs. $3 \mathrm{a}$ and $3 \mathrm{~b}$ ), the detonation reaches a steady propagation speed of 1928 and $1932 \mathrm{~m} / \mathrm{s}$, respectively, after the initial transient phase. With the finest two grids used in this study (figs $3 \mathrm{c}$ and $3 \mathrm{~d}$ ), the detonation reaches a high-frequency, low-amplitude propagation mode. Table 2 summarizes the results of the grid refinement study. The final average detonation speed is essentially independent of the grid spacing. The frequency and amplitude of the oscillations are also nearly identical for the two finest grids. All subsequent calculations were carried out on the finest grid.

The theoretical Chapman-Jouguet detonation speed for this mixture, as computed with $\mathrm{CEA}^{22}$, is $D_{C J}=1799.4 \mathrm{~m} / \mathrm{s}$. Therefore, the results presented in figs. 5 and 6 are actually those of an overdriven detonation, with a degree of overdrive $f=1.15$.

The high-frequency mode of oscillation can be explained by the McVey-Toong wave interaction mechanism ${ }^{12}$. Two fundamental processes form the basis of this mechanism: (i) when a new reaction front is created, compression waves (reaction shocks) are generated that travel upstream and downstream from the new reaction front; (ii) when an old reaction front is extinguished, it must be accompanied by the generation of upstream and downstream rarefaction waves that have a strength comparable to the reaction shocks. The interaction between these waves and the shock front produces the high-frequency oscillations. 


\section{Equivalence ratio effect}

Parametric studies were carried out over an equivalence ratio range of $0.5 \leq \phi \leq 3$ for ethylene-air mixtures at $p_{0}=0.2$ bar and $T_{0}=298 \mathrm{~K}$ and a driver pressure ratio of 150. The results are shown in figs.4-7, and summarized in Table 3.

Figure 4 shows the variation of detonation speed with time for several lean mixtures. The structure of the detonation for all the lean mixtures considered is very similar to that observed for the stoichiometric case. The frequency of oscillation, $\omega$, decreases monotonically from $0.36 \mathrm{MHz}$ for $\phi=1.0$ to $0.20 \mathrm{MHz}$ for $\phi=0.5$ (see Table 3). Note that although the driver pressure ratio is fixed at 150 , the degree of overdrive increases for leaner mixtures.

Figure 5, which gives the shock pressure as a function of time for the same ethylene-air mixtures as in fig. 4, shows that the average shock pressure decreases for leaner mixtures, but the normalized oscillation pressure amplitude remains nearly constant. The oscillation amplitude is computed from the peak-to-trough shock pressure normalized by the average shock pressure.

Figures 6 and 7 show the variations in detonation wave speed and shock pressure with time for rich mixtures. Note that the maximum oscillation frequency is obtained for $\phi=1.2$, and the maximum normalized oscillation pressure amplitude is obtained for $\phi=1.6$. The degree of overdrive remains nearly constant for all mixtures. For $\phi>1.2$, the detonation wave exhibits the long-period mode of instability, characterized by low-frequency, high-amplitude oscillations, that is, a "galloping" propagation mode. Both the amplitude and frequency of oscillation decrease for richer mixtures. The frequency of oscillation of the long-period mode is an order of magnitude lower than that obtained for the short-period mode. Note also that for the $\phi=1.6$ and 3.0 cases high-frequency oscillations appear first, but then disappear once the long-period mode is fully established. High-frequency oscillations are also apparent for the two richest mixtures during the portion of the long-period cycle when the shock pressure is highest.

\section{Initial Pressure effect}

The effect of initial pressure on detonation wave structure was examined by studying its behavior at a higher initial pressure ( $\left.p_{0}=0.4 \mathrm{bar}, T_{0}=298 \mathrm{~K}\right)$. The results are shown in fig. 8 and summarized in Table 4 . For the driver pressure ratio considered $\left(r_{p}=150\right)$, the degree of overdrive ranges from 1.29 for $\phi=0.6$ to 1.12 for the two rich mixtures.

The structure of the detonation wave at the higher pressure (fig. 8 ) is similar to that for the $p_{0}=0.2$ bar case (figs. 4 and 6), but the frequencies of oscillation are much higher. The effect of equivalence ratio on oscillation frequency is more pronounced at the higher pressure. For $\phi=1.0$ the frequency is $0.74 \mathrm{MHz}$, and it decreases to $0.475 \mathrm{MHz}$ for $\phi=0.6$. For $\phi=1.2$ the short-period mode appears first, but it subsequently switches to the long-period mode at longer times. Further mixture enrichment $(\phi=1.4)$ produces only the long-period mode.

\section{Driver pressure ratio effect}

The effect of driver pressure ratio, $r_{p}$, on detonation wave structure was investigated for stoichiometric ethylene-air mixtures at $p_{0}=0.2$ bar. Figure 9 shows the detonation shock pressure as a function of time for several driver pressure ratios.

For the two lowest driver pressure ratios $\left(r_{p}=70\right.$ and 100) the detonation wave initially exhibits the short-period oscillation mode, but it appears to be transitioning to the long-period mode at longer times. For driver pressure ratios between 150 and 250 (figs. 9c-9e) the detonation wave exhibits only the short-period propagation mode during the time frame considered. Table 5 summarizes the oscillation frequency and amplitude for all the cases shown in fig. 9. The frequency of oscillation increases and the amplitude decreases with increasing driver pressure ratio. At driver pressure ratios of 275 and above, the high-frequency oscillations are observed to decay with time; that is, the detonation wave is stabilized at high degrees of overdrive. This behavior has also been observed by Bourlioux et al. ${ }^{4}$ using one-step Arrhenius kinetics.

\section{Comparison with Theory}

As discussed previously, the short-period mode, described by the McVey-Toong mechanism, results from the successive interactions of reaction shocks and expansion waves with the lead shock. The resulting oscillation period, $T_{m t}$, is the sum of the ignition delay time, $t_{i}$, and the time required for the reaction shock to overtake the lead shock. Implicit in their mechanism is the assumption of negligible heat release time relative to the ignition delay time; that is, the (single) reaction shock is created immediately upon ignition. For the one-dimensional detonation flows considered here, $T_{m t}$ is given by Alpert $\&$ Toong ${ }^{23}$ as follows:

$$
T_{m t}=\frac{t_{i}}{\left(1-M_{s}\right)}
$$

where $M_{s}$ is the Mach number immediately behind the lead shock. Therefore, the frequency of oscillation, $\omega\left(=1 / T_{m t}\right)$, is inversely proportional to the ignition delay time. 
Figure 10 shows a comparison of the computed short-period frequency of oscillation with that given by equation 5, as a function of equivalence ratio for the short-period cases discussed previously. The ignition delay time is arbitrarily defined as the time required for the temperature of the gas to increase by $25 \mathrm{~K}$, and was computed using the chemical kinetics code LSENS ${ }^{24-26}$. The frequencies given by the McVey-Toong short-period wave-interaction theory are in good agreement with the computed frequencies for lean mixtures at low pressures. However, the frequencies given by equation 5 are much higher for near-stoichiometric and rich mixtures, especially at the higher pressure. Thus the largest differences between the computed and theoretical frequencies of oscillation occur for conditions with the shortest ignition delay time.

The deviation of the McVey-Toong theory (equation 5) from the computed frequency has been attributed to neglect of the heat release time, an assumption that is not always valid since there are many situations in which the heat release time is a significant fraction of the total reaction time $^{11}$. Modification of the McVey-Toong theory to account for the finite heat-release time was proposed in which a modified oscillation period, $T_{m m t}$, is computed as follows ${ }^{11}$ :

$$
T_{m m t}=\frac{t_{i}}{\left(1-M_{s}\right)}+\alpha \Delta t_{\text {qmax }}
$$

where $\Delta t_{\mathrm{qmax}}$ is the interval between ignition and maximum rate of heat release and $\alpha$ is an empirical constant. In ref. 11, which considered hydrogen-air mixtures only, $\alpha$ was estimated by least-squares minimization to be equal to 0.6 .

The frequencies of oscillation obtained from equation 6 for the ethylene-air mixtures considered in the present study, using the same value of $\alpha(=0.6)$ as for the hydrogen-air mixtures considered in ref. 11 are also plotted in figure 10 . Note that accounting for the finite heat-release time has resulted in significant improvements in the theoretical frequencies, when compared with the numerical results. In fact, the agreement between the modified theory and the computations is excellent over the entire equivalence ratio and pressure ranges.

\section{Conclusions}

The one-dimensional Euler equations with detailed finite rate chemistry were solved numerically to investigate the structure and stability of detonation waves in ethylene-air mixtures. Parametric studies over a range of fuel-air equivalence ratios, initial pressures and degrees of detonation overdrive indicate that one-dimensional ethylene-air detonation waves exhibit unsteady oscillatory propagation modes for low degrees of overdrive. For lean to slightly rich $(\phi \approx 1.2)$ mixtures the detonation wave propagates in a high-frequency low-amplitude mode, as described by the McVey-Toong short-period mechanism. For richer mixtures the detonation wave switches to a 'galloping' long-period mode characterized by low-frequency, high-amplitude oscillations.

High degrees of overdrive stabilized the detonation wave: the high-frequency oscillations decayed with time and the detonation wave propagated in a stable mode. Calculations with very low degrees of overdrive resulted in complex, irregular oscillations, possibly transitioning to the long-period mode.

The frequencies of oscillation obtained with the McVey-Toong short-period wave-interaction theory are much higher than those obtained from the detailed numerical simulations, especially for near-stoichiometric mixtures at high pressure. This difference is attributed to the implicit assumption in the McVey-Toong theory that the heat release period is negligibly small compared with the ignition delay time. Modification of their theory to account for the finite heat-release time resulted in excellent agreement with the numerical simulations for all conditions. Exactly the same modification has been shown to be effective for hydrogen-air mixtures.

\section{References}

1. Williams, F. A., Combustion Theory. Addison-Wesley, 1985.

2. Fickett, W. and Wood, W.W., "Flow Calculations for Pulsating One-Dimensional Detonations," Physics of Fluids, Vol. 9, pp. 903-916, 1966.

3. Abouseif, G. and Toong, T.Y., "Theory of Unstable One-Dimensional Detonations," Combustion and Flame, Vol. 45, pp. 64-94, 1982.

4. Bourlioux, A., Majda, A.J. and Roytburd, V., "Theoretical and Numerical Structure of Unstable One-Dimensional Detonations," SIAM Journal of Applied Mathematics, Vol. 51, pp. 303-343, April 1991.

5. Fickett, W., Jacobson, J.D. and Schott, G.L., "Calculated Pulsating One-Dimensional Detonations with Induction-Zone Kinetics," AIAA Journal, Vol. 10, pp. 514-516, 1972.

6. Short, M. and Quirk, J.J., "On the Nonlinear Stability and Detonability Limit of a Detonation Wave for a Model Three-Step Chain-Branching Reaction, “Journal of Fluid Mechanics, Vol. 339, pp. 89-119, 1997. 
7. Sanchez, A.L., Carretero, M., Clavin, P. and Williams, F.A., "One-Dimensional Overdriven Detonations with Branched-Chain Kinetics. Physics of Fluids Vol. 13, pp. 776-792, 2001.

8. Sussman, M.A., "A Computational Study of Unsteady Shock Induced Combustion of Hydrogen-Air Mixtures," AIAA paper 94-3101, June 1994.

9. He, L., "Theoretical Determination of the Critical Conditions for the Direct Initiation of Detonations in Hydrogen-Oxygen Mixtures," Combustion and Flame, Vol. 104, pp. 401-418, 1996.

10. Yungster, S. and Radhakrishnan, K., "Computational Study of Near-Limit Propagation of Detonation in Hydrogen-Air Mixtures," AIAA paper 2002-3712, July 2002.

11. Yungster, S. and Radhakrishnan, K., "Pulsating One-Dimensional Detonations in Hydrogen-Air Mixtures," in preparation.

12. McVey, J.B. and Toong, T.Y., "Mechanism of Instabilities of Exothermic Hypersonic Blunt Body Flows," Combustion Science and Technology, Vol. 3, pp. 63-76, 1971.

13. Lehr, H.F., "Experiments on Shock-Induced Combustion," Acta Astronautica, Vol. 17, 1972, pp. 589-597.

14. Daniau, E., Zitoun, R., Couquet, C. and Desbordes, D., "Effects of Nozzles of Different Length and Shape on the Propulsion Performance of Pulsed Detonation Engines," in High-Speed Deflagration and Detonation, Eds. G.D. Roy, S.M. Frolov, D. Netzer and A. Borisov. Moscow, 2001: ELEX-KM Publ. pp 251-262.

15. Jenkins, T.P., Sanders, S.T., Baldwin, J.A., Fan, W., Baer, D.S. and Hanson, R.K., "Diode-Laser Based Sensors for Pulsed Detonation Engine Flows," in High-Speed Deflagration and Detonation, Eds. G.D. Roy, S.M. Frolov, D. Netzer and A. Borisov. Moscow, 2001: ELEX-KM Publ. pp 273-288.

16. Li, S.C., Varatharajan, B. and Williams, F.A., "The Chemistry of Ethylene Ignition for Application to Pulse Detonation Engines," AIAA paper 2000-3475, July 2000.
17. Yee, H.C., "Construction of Explicit and Implicit Symmetric TVD Schemes and Their Applications," Journal of Computational Physics, Vol. 68, 1987, pp. 151-179.

18. Yungster, S. and Radhakrishnan, K., "A Fully Implicit Time Accurate Method for Hypersonic Combustion: Application to Shock-Induced Combustion Instability," Shock Waves, Vol. 5, 1996, pp. 293-303.

19. Wilson, G.J. and Sussman, M.A., "Computation of Unsteady Shock-Induced Combustion Using Logarithmic Species Conservation Equations," AIAA Journal, Vol. 31, pp. 294-301, February 1993.

20. Matsuo, A. and Fujii, K., "Detailed Mechanism of the Unsteady Combustion Around Hypersonic Projectiles," AIAA Journal, Vol. 34, pp. 2082-2089, October 1996.

21. Povinelli, L.A. and Yungster, S., "Real Gas Effects on the Performance of Hydrocarbon-Fueled Pulse Detonation Engines," AIAA paper 2003-0712, January 2003.

22. McBride, B.J. and Gordon, S., "Computer Program for Calculation of Complex Chemical Equilibrium Compositions and Applications. II. Users Manual and Program Description,” NASA RP-1311, 1996.

23. Alpert, R. L. and Toong, T. Y., "Periodicity in Exhothermic Hypersonic Flows About Blunt Projectiles," Acta Astronautica, Vol. 17, pp. 538-560, 1972.

24. Radhakrishnan, K., "Combustion Kinetics and Sensivity Analysis Computations," in Numerical Approaches to Combustion, E.S. Oran and J.P. Boris, Eds., AIAA, Washington, DC, 1991, pp. 83-128.

25. Radhakrishnan, K., "LSENS-A General Chemical Kinetics and Sensitivity Analysis Code for Homogeneous Gas-Phase Reactions. I. Theory and Numerical Solution Procedures," NASA RP-1328, 1994.

26. Radhakrishnan, K., "LSENS: Multipurpose Kinetics and Sensitivity Analysis Code for Homogeneous Gas-Phase Reactions," AIAA Journal, Vol. 41, No. 5, pp. 848-855, May 2003. 
Table 1: Short Chemical-Kinetic Mechanism for $\mathrm{C}_{2} \mathrm{H}_{4}$ Ignition and Detonation (Li et al. ${ }^{16}$ ).

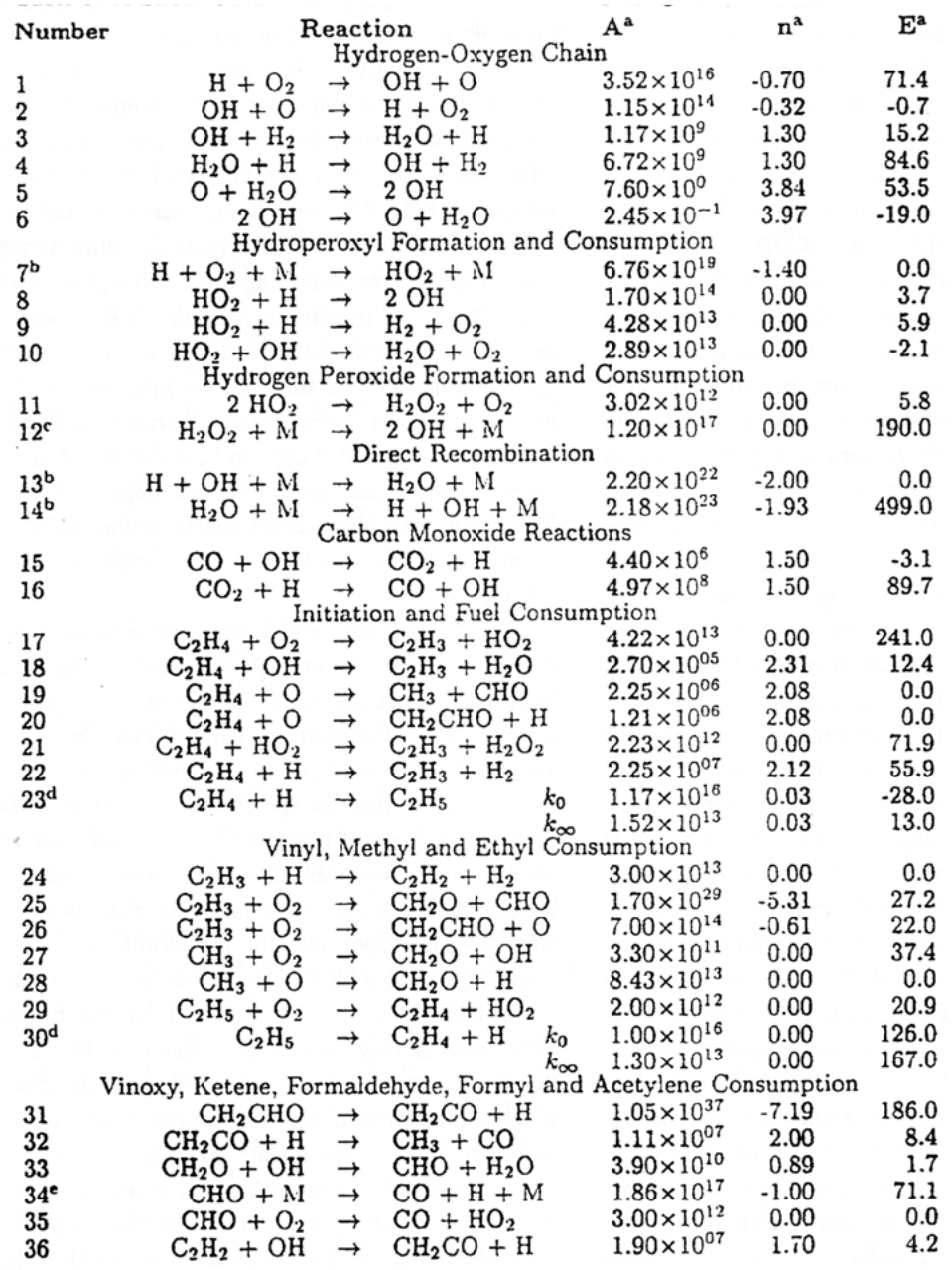

Apecific reaction-rate constant $k=A T^{n} e^{-E / R T}$; units $\mathrm{mol}, \mathrm{cm}^{3}, \mathrm{~s}, \mathrm{~K}$ and $\mathrm{kJ} / \mathrm{mol}$.

'Chaperon efficiencies: $\mathrm{CO}, 1.9 ; \mathrm{CO}_{2}, 3.8 ; \mathrm{H}_{2}, 2.5 ; \mathrm{H}_{2} \mathrm{O}, 12.0$; others, 1.0

c Chaperon efficiencies: Same as $b$ above except $\mathrm{H}_{2} \mathrm{O}, 16.3$.

¿Falloff from Hewson and Villiams

- Chaperon efficiencies: $\mathrm{CO}, 2.5 ; \mathrm{CO}_{2}, 2.5 ; \mathrm{H}_{2}, 1.9 ; \mathrm{H}_{2} \mathrm{O}, 12.0$; others, 1.0 .

Table 2: Oscillation frequency and amplitude for various grid spacings $(f=1.15)$

\begin{tabular}{c|c|c|c|c}
\hline Figure & $\begin{array}{c}\text { Minimum grid spacing } \\
(\mathrm{cm})\end{array}$ & $\begin{array}{c}\text { Average propagation speed } \\
(\mathrm{m} / \mathrm{s})\end{array}$ & $\begin{array}{c}\text { Oscillation frequency } \\
(\mathrm{MHz})\end{array}$ & $\begin{array}{c}\text { Oscillation amplitude } \\
\Delta D / \bar{D}\end{array}$ \\
\hline \hline $3 \mathrm{a}$ & $3.906 \times 10^{-3}$ & 1928 & - & - \\
\hline $3 \mathrm{~b}$ & $1.953 \times 10^{-3}$ & 1932 & 0.36 & 0.091 \\
\hline $3 \mathrm{c}$ & $9.766 \times 10^{-4}$ & 1931 & 0.36 & 0.092 \\
\hline $3 \mathrm{~d}$ & $4.883 \times 10^{-4}$ & 1929 & & - \\
\hline
\end{tabular}


Table 3: Oscillation frequency and amplitude for various equivalence ratios $\left(p_{0}=0.2\right.$ bar; $\left.r_{p}=150\right)$

\begin{tabular}{|c|c|c|c|c|c|}
\hline Figure & $\begin{array}{l}\text { Equivalence } \\
\text { ratio }(\phi)\end{array}$ & $D_{C J}(\mathrm{~m} / \mathrm{s})$ & $\begin{array}{c}\text { Degree of } \\
\text { overdrive }(f)\end{array}$ & $\begin{array}{l}\text { Oscillation frequency } \\
\qquad(\omega, \mathrm{MHz})\end{array}$ & $\begin{array}{l}\text { Oscillation amplitude } \\
\qquad(\Delta p / \bar{p})\end{array}$ \\
\hline $4 \& 5$ (f) & 0.5 & 1539.6 & 1.36 & 0.20 & 0.19 \\
\hline $4 \& 5$ (e) & 0.6 & 1624.5 & 1.27 & 0.24 & 0.18 \\
\hline $4 \& 5(d)$ & 0.7 & 1687.0 & 1.22 & 0.28 & 0.18 \\
\hline $4 \& 5$ (c) & 0.8 & 1733.8 & 1.19 & 0.31 & 0.20 \\
\hline $4 \& 5$ (b) & 0.9 & 1770.2 & 1.16 & 0.345 & 0.19 \\
\hline $4 \& 5(a)$ & 1.0 & 1799.4 & 1.15 & 0.36 & 0.20 \\
\hline $6 \& 7$ (a) & 1.2 & 1841.5 & 1.13 & 0.40 & 0.17 \\
\hline $6 \& 7$ (b) & 1.4 & 1864.4 & 1.11 & 0.068 & 0.82 \\
\hline $6 \& 7$ (c) & 1.6 & 1869.9 & 1.12 & 0.058 & 1.17 \\
\hline $6 \& 7(d)$ & 2.0 & 1853.0 & 1.13 & 0.036 & 1.01 \\
\hline $6 \& 7$ (e) & 3.0 & 1747.7 & 1.12 & 0.021 & 0.56 \\
\hline
\end{tabular}

Table 4: Oscillation frequency and amplitude for various equivalence ratios $\left(p_{0}=0.4\right.$ bar; $\left.r_{p}=150\right)$

\begin{tabular}{c|c|c|c|c}
\hline Figure & $\begin{array}{c}\text { Equivalence } \\
\text { ratio }(\phi)\end{array}$ & $D_{C J}(\mathrm{~m} / \mathrm{s})$ & $\begin{array}{c}\text { Degree of } \\
\text { overdrive }(f)\end{array}$ & $\begin{array}{c}\text { Oscillation frequency } \\
(\omega, \mathrm{MHz})\end{array}$ \\
\hline \hline $8(\mathrm{a})$ & 0.6 & 1629.4 & 1.29 & 0.475 \\
\hline $8(\mathrm{~b})$ & 0.8 & 1745.5 & 1.20 & 0.63 \\
\hline $8(\mathrm{c})$ & 1.0 & 1814.5 & 1.16 & 0.74 \\
\hline $8(\mathrm{~d})$ & 1.2 & 1857.0 & 1.12 & $0.80,0.13$ \\
\hline $8(\mathrm{e})$ & 1.4 & 1877.3 & 1.12 & 0.12 \\
\hline
\end{tabular}


Table 5: Oscillation frequency and amplitude for various driver pressure ratios $\left(p_{0}=0.2\right.$ bar; $\left.\phi=1\right)$

\begin{tabular}{c|c|c|c|c}
\hline Figure & $\begin{array}{c}\text { Driver pressure } \\
\text { ratio }\left(r_{\mathrm{p}}\right)\end{array}$ & $\begin{array}{c}\text { Degree of } \\
\text { overdrive }(f)\end{array}$ & $\begin{array}{c}\text { Oscillation frequency } \\
(\omega, \mathrm{MHz})\end{array}$ & $\begin{array}{c}\text { Oscillation amplitude } \\
(\Delta p / \bar{p})\end{array}$ \\
\hline \hline $9 \mathrm{a}$ & 70 & $\sim 1.04$ & transitioning & 0.849 \\
\hline $9 \mathrm{~b}$ & 100 & $\sim 1.07$ & transitioning & 0.306 \\
\hline $9 \mathrm{c}$ & 150 & 1.15 & 0.36 & 0.192 \\
\hline $9 \mathrm{~d}$ & 200 & 1.22 & 0.48 & 0.160 \\
\hline $9 \mathrm{e}$ & 250 & 1.29 & 0.59 & vanishing \\
\hline $9 \mathrm{f}$ & 275 & 1.32 & 0.64 & - \\
\hline $9 \mathrm{~g}$ & 300 & 1.35 & stable & - \\
\hline $9 \mathrm{~h}$ & 400 & 1.45 & stable & \\
\hline
\end{tabular}


(a)
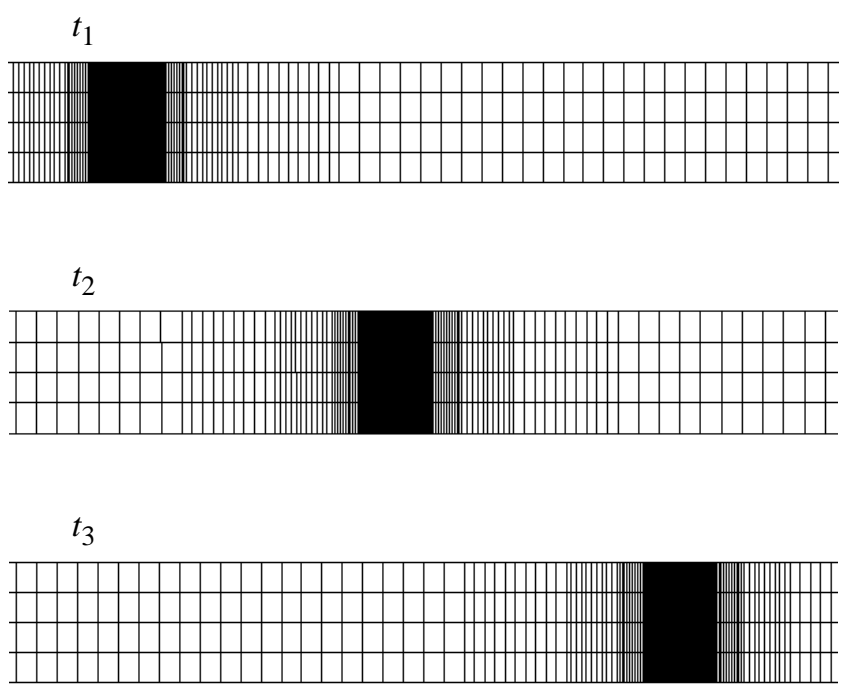

Fig. 1. Computational grid at three different times.

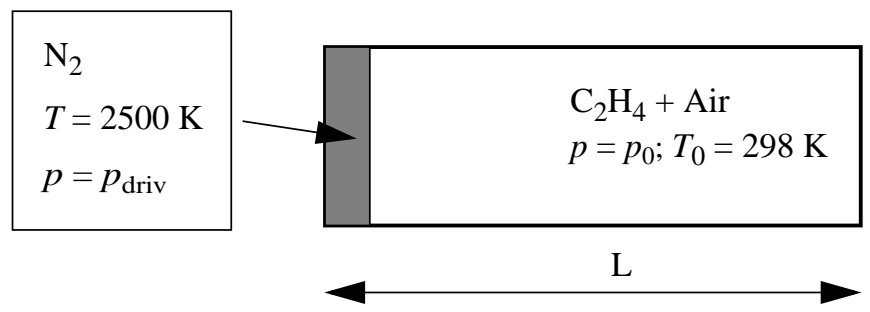

Fig. 2. Schematic of detonation wave initiation.

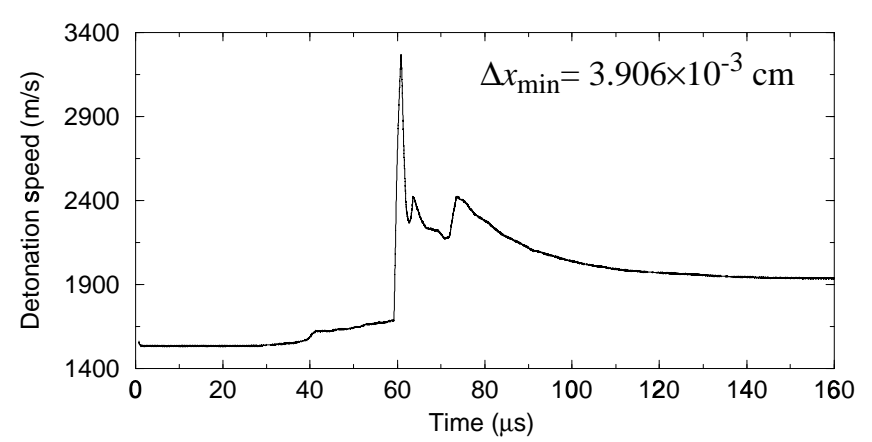

(b)

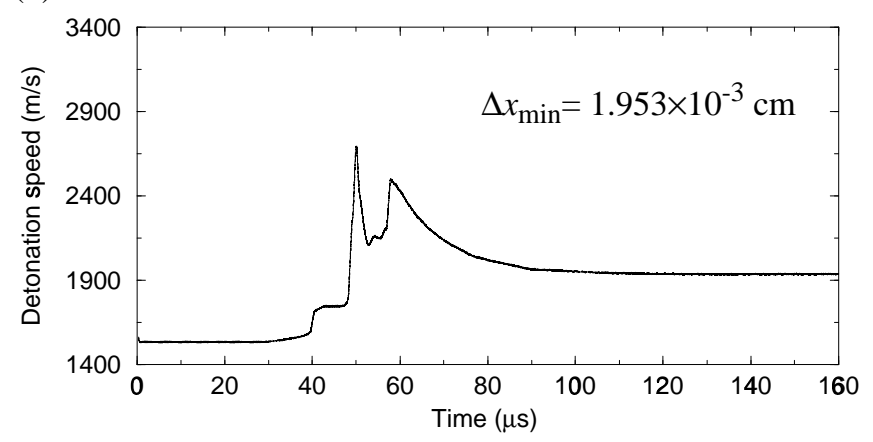

(c)

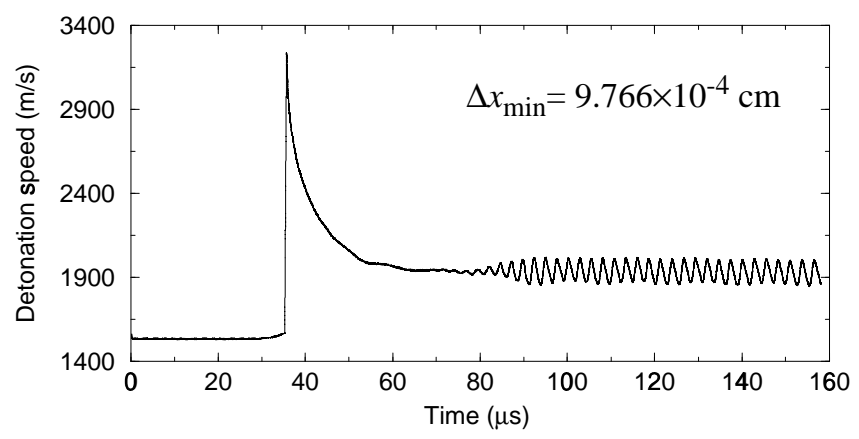

(d)

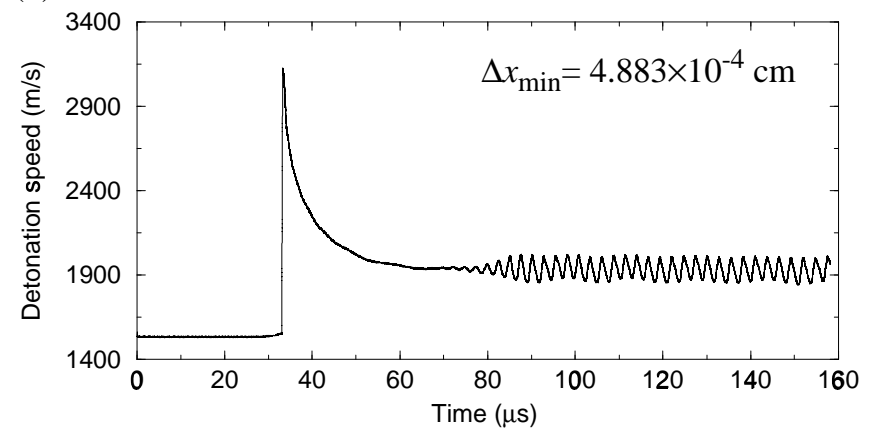

Fig. 3. Effect of grid spacing on detonation wave solution. $\mathrm{C}_{2} \mathrm{H}_{4}$-Air; $p_{0}=0.2$ bar; $\phi=1.0 ; r_{p}=p_{\text {driv }} / p_{0}=150 ; D_{C J}=$ $1799.4 \mathrm{~m} / \mathrm{s} ; f=1.15$. 
(a)

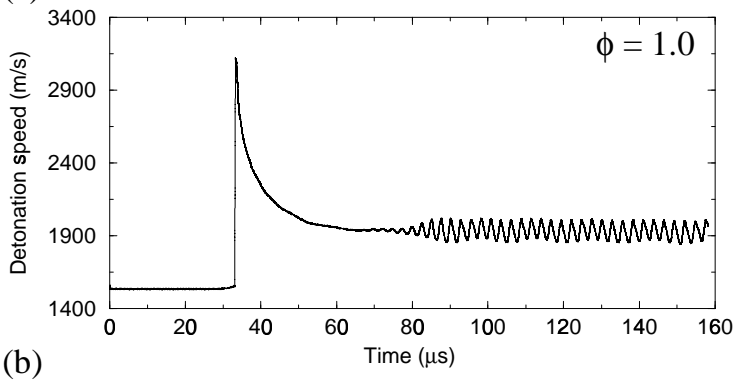

(b)

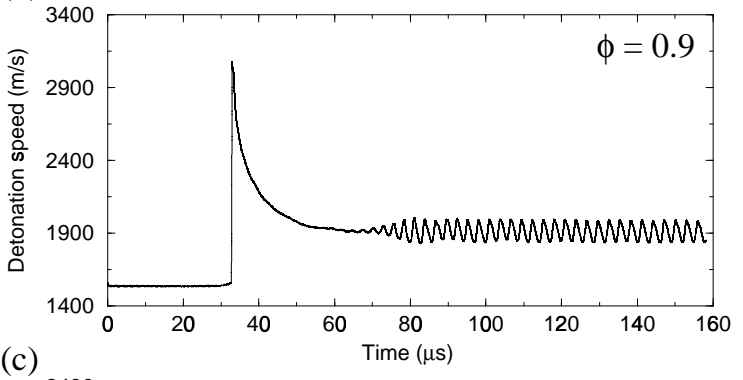

(c)

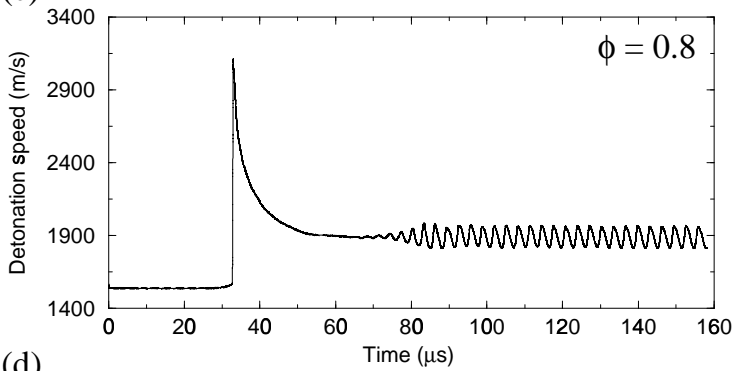

(d)

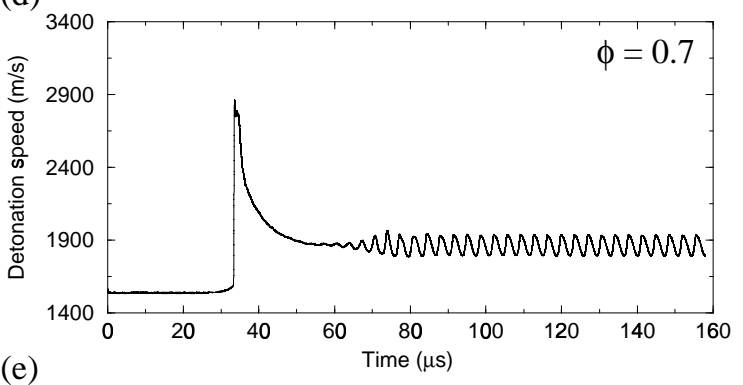

(e)

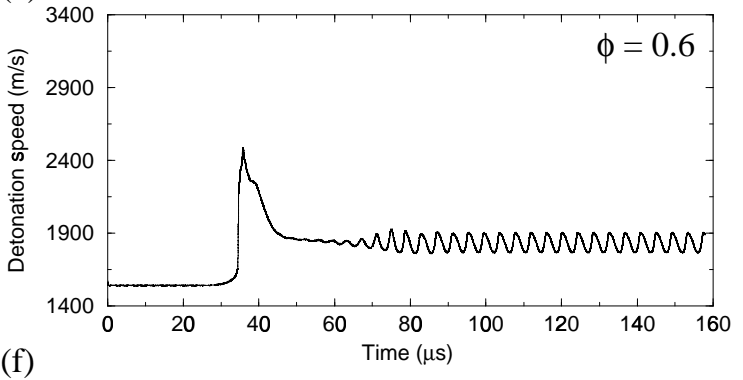

(f)

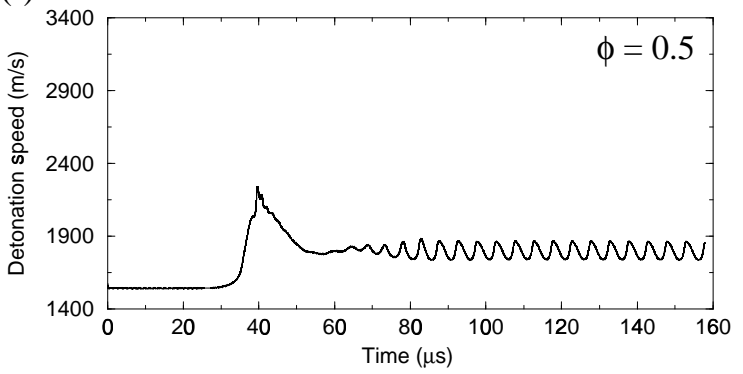

Fig. 4. Detonation speed as a function of time; $\mathrm{C}_{2} \mathrm{H}_{4}$-Air; $p_{0}=0.2$ bar; $r_{p}=p_{\text {driv }} / p_{0}=150 ; \Delta x_{\min }=4.883 \times 10^{-4} \mathrm{~cm}$. (a)

(b)
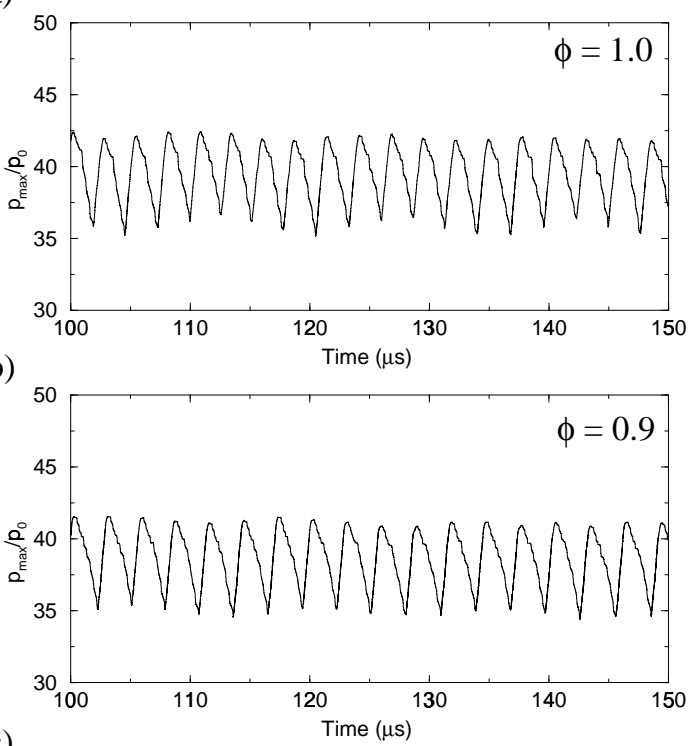

(c)

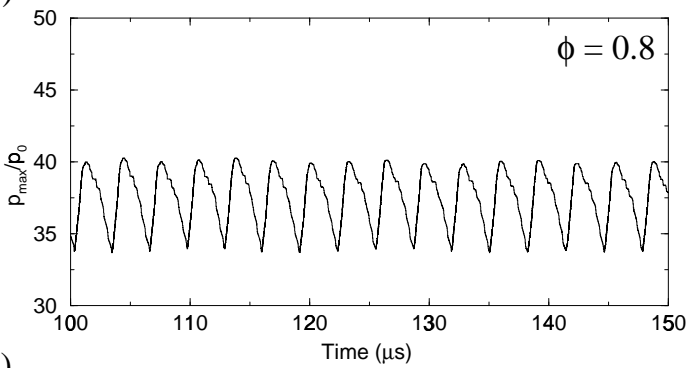

(d)

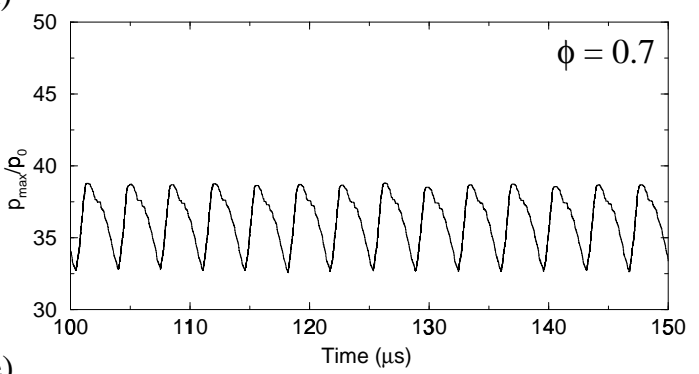

(e)
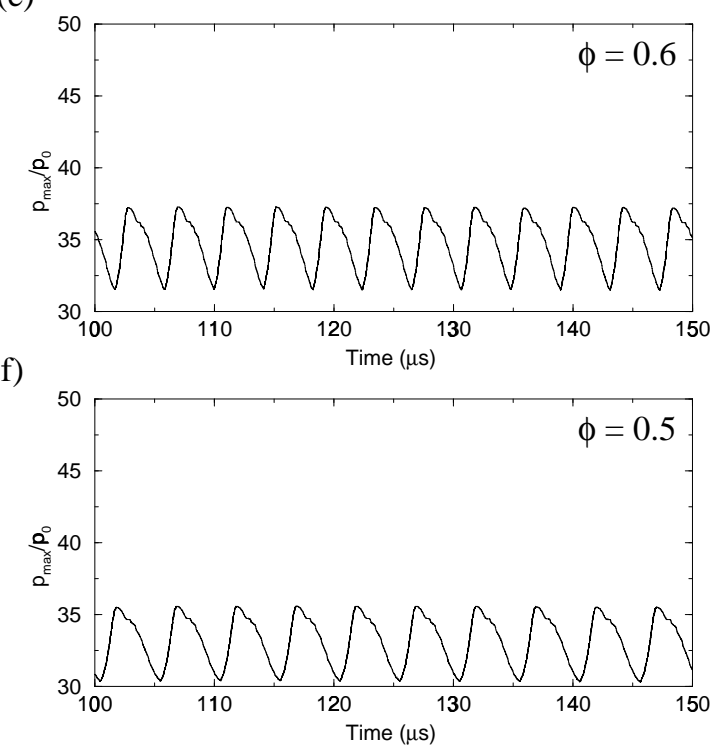

Fig. 5. Normalized shock pressure as a function of time; $\mathrm{C}_{2} \mathrm{H}_{4}$-Air; $p_{0}=0.2$ bar; $r_{p}=150 ; \Delta x_{\min }=4.883 \times 10^{-4} \mathrm{~cm}$. 
(a)

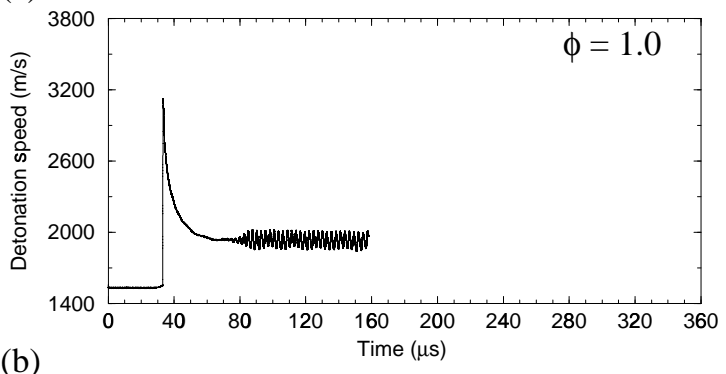

(b)

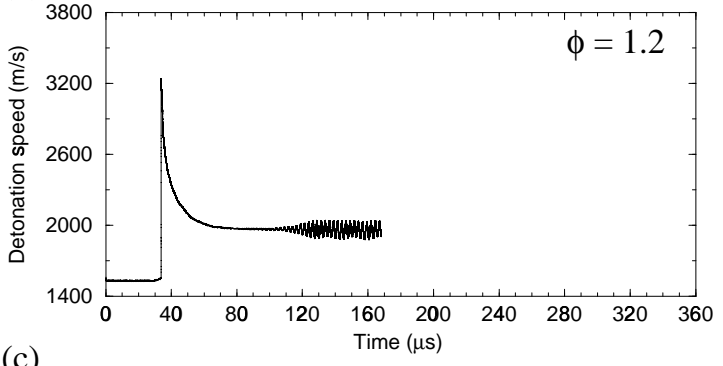

(c)

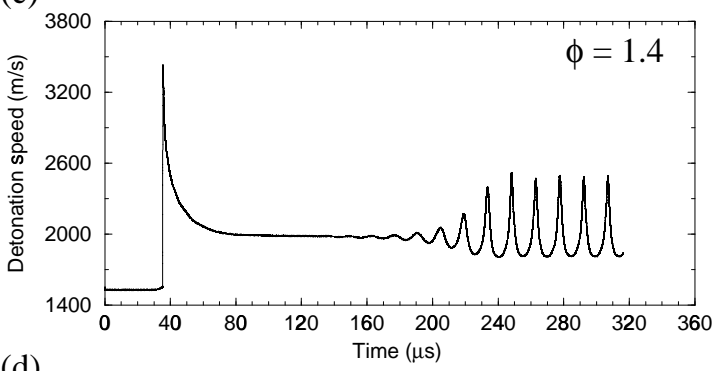

(d)

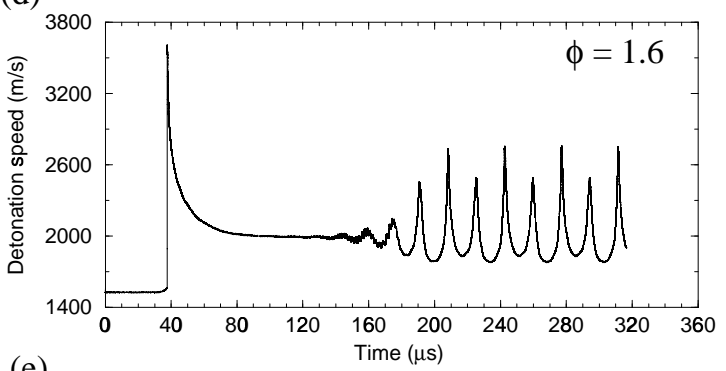

(e)

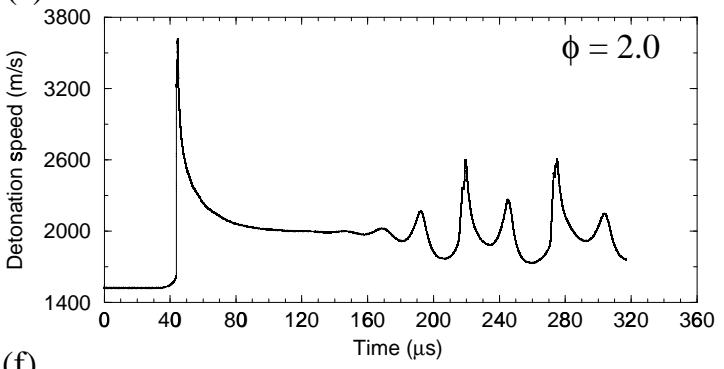

(f)

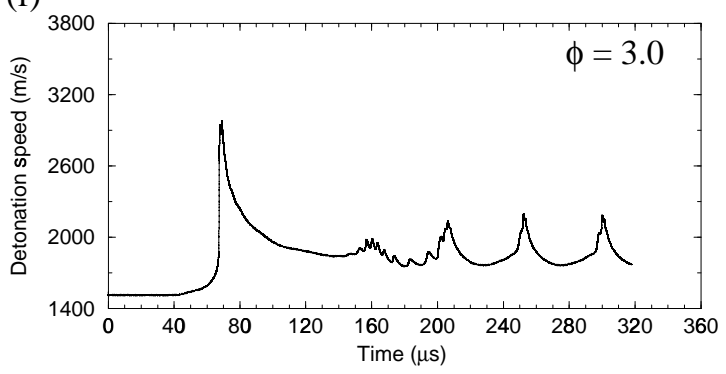

Fig. 6. Detonation speed as a function of time; $\mathrm{C}_{2} \mathrm{H}_{4}$-Air; $p_{0}=0.2$ bar; $r_{p}=p_{d r i v} / p_{0}=150 ; \Delta x_{\min }=4.883 \times 10^{-4} \mathrm{~cm}$. (a)

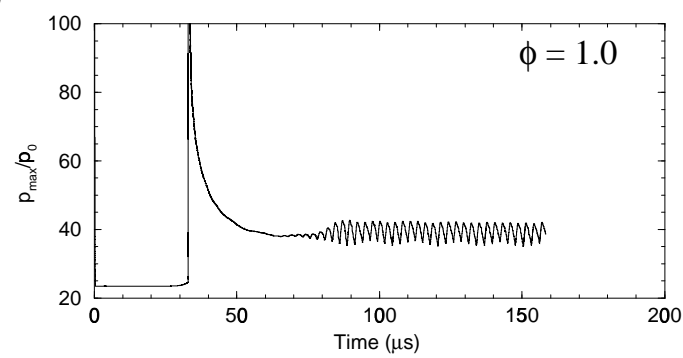

(b)

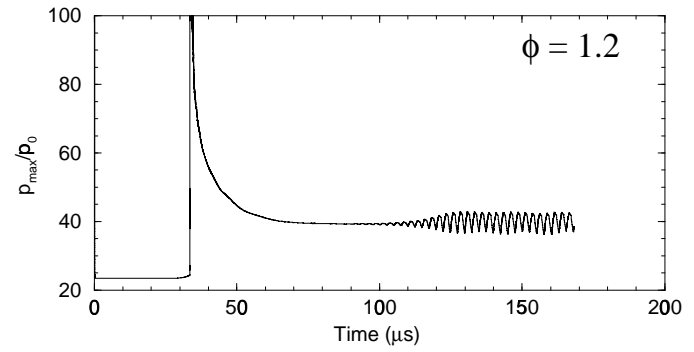

(c)

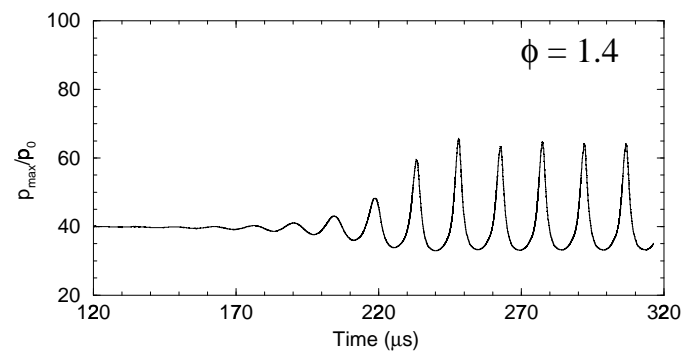

(d)

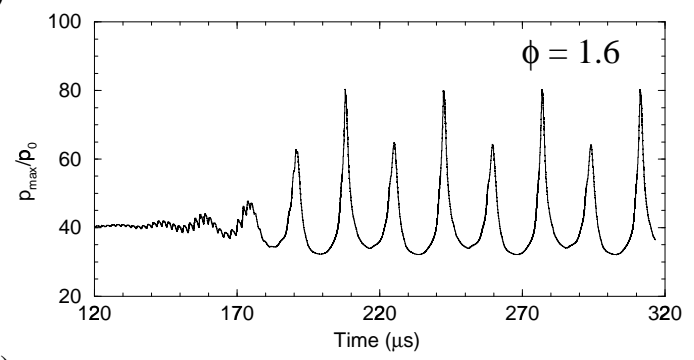

(e)

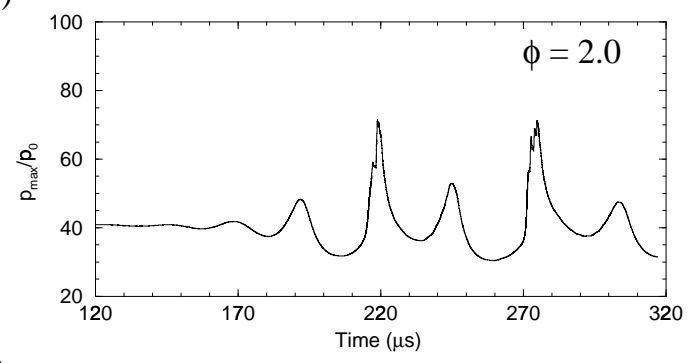

(f)

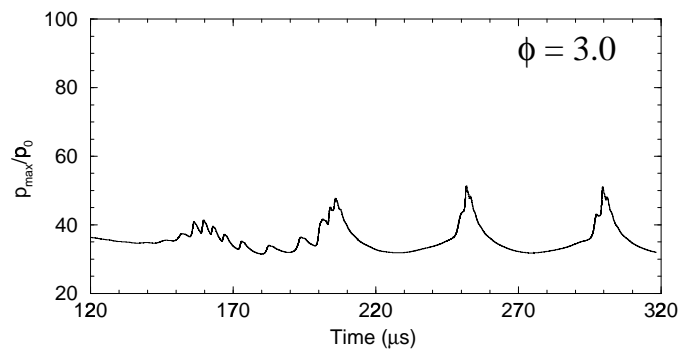

Fig. 7. Normalized shock pressure as a function of time; $\mathrm{C}_{2} \mathrm{H}_{4}$-Air; $p_{0}=0.2$ bar; $r_{p}=150 ; \Delta x_{\min }=4.883 \times 10^{-4} \mathrm{~cm}$. 
(a)

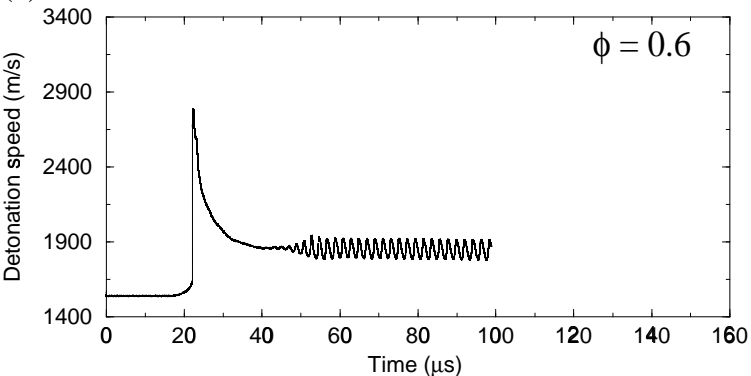

(b)

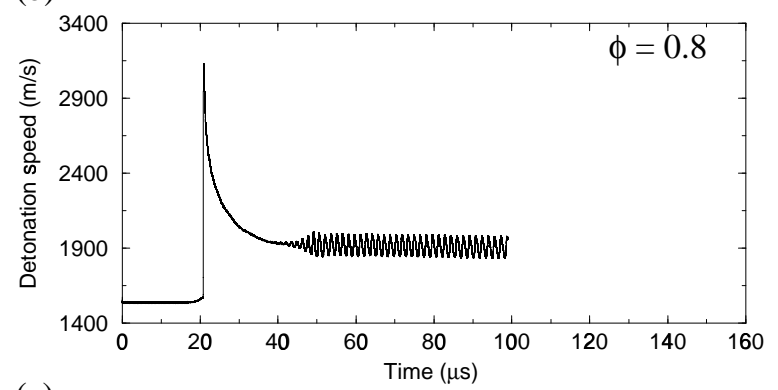

(c)

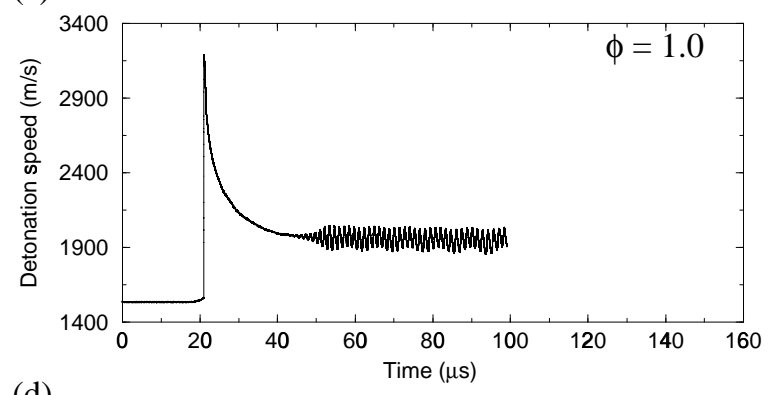

(d)

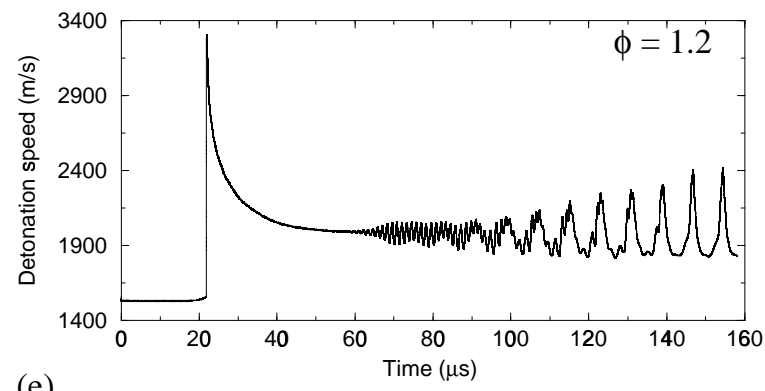

(e)

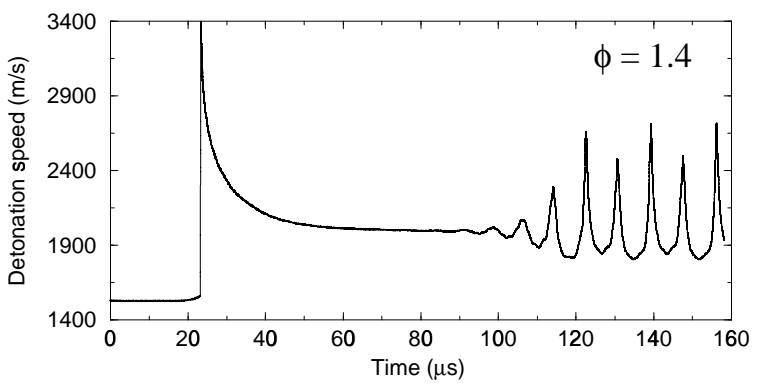

(a)

(b)

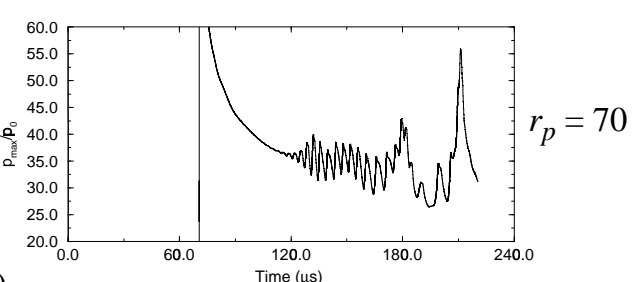

b) 42.0

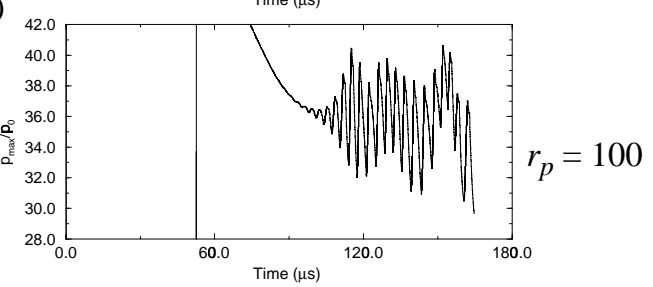

(c)

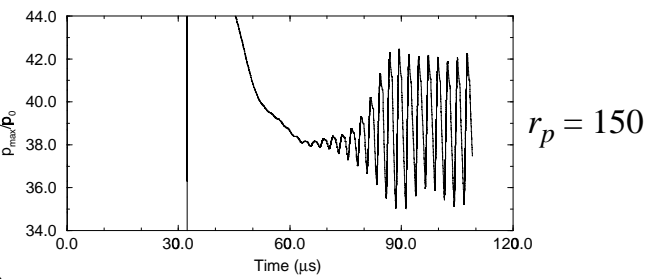

(d)

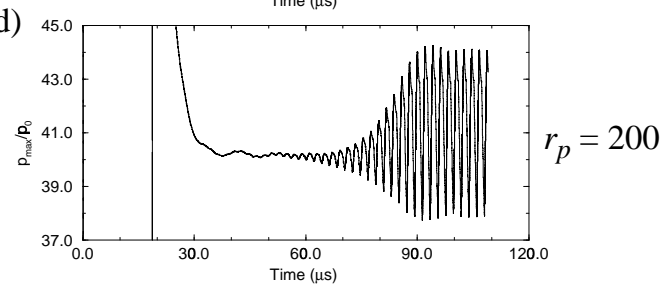

(e)

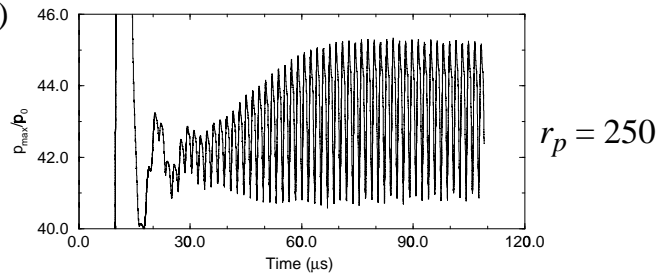

(f)

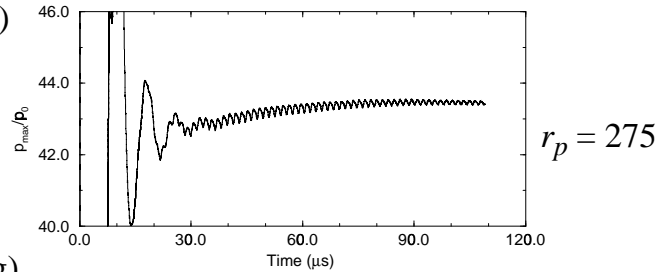

(g)

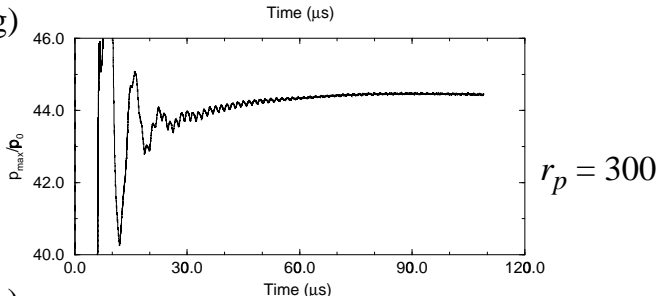

(h)

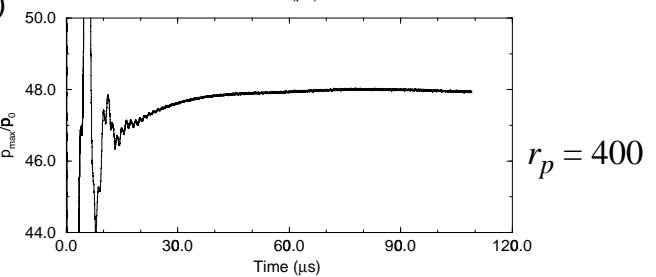

Fig. 8. Detonation speed as a function of time; $\mathrm{C}_{2} \mathrm{H}_{4}$-Air; $p_{0}=0.4$ bar; $r_{p}=p_{\text {driv }} / p_{0}=150 ; \Delta x_{\min }=4.883 \times 10^{-4} \mathrm{~cm}$.
Fig. 9. Normalized shock pressure $\left(p_{\max } / p_{0}\right)$ as a function of time; $\mathrm{C}_{2} \mathrm{H}_{4}$-Air; $p_{0}=0.2$ bar; $\phi=1 ; \Delta x_{\min }=4.883 \times 10^{-4} \mathrm{~cm}$. 


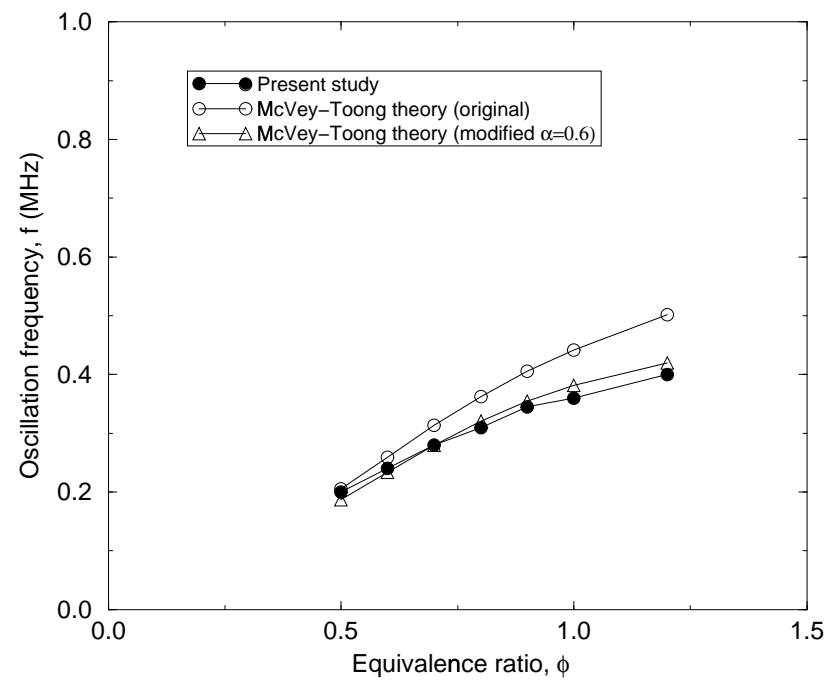

Fig. 10. Short-period frequency of oscillation; comparison between computed frequencies (present study) and those obtained from the original and modified McVey-Toong theories. $\mathrm{C}_{2} \mathrm{H}_{4}$-Air; $p_{0}=0.2$ bar, $r_{p}=150$.

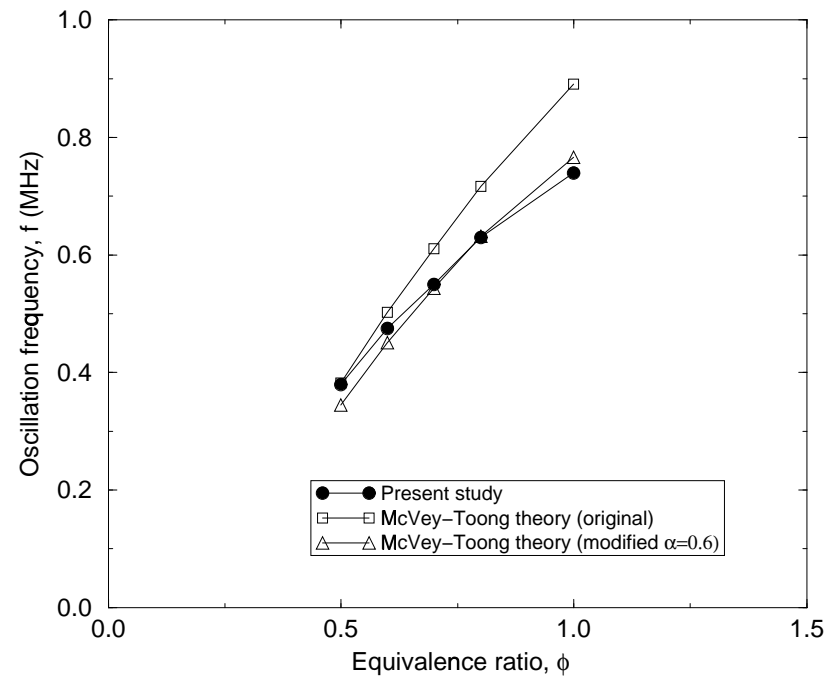

Fig. 11. Short-period frequency of oscillation; comparison between computed frequencies (present study) and those obtained from the original and modified McVey-Toong theories. $\mathrm{C}_{2} \mathrm{H}_{4}$-Air; $p_{0}=0.4$ bar, $r_{p}=150$. 


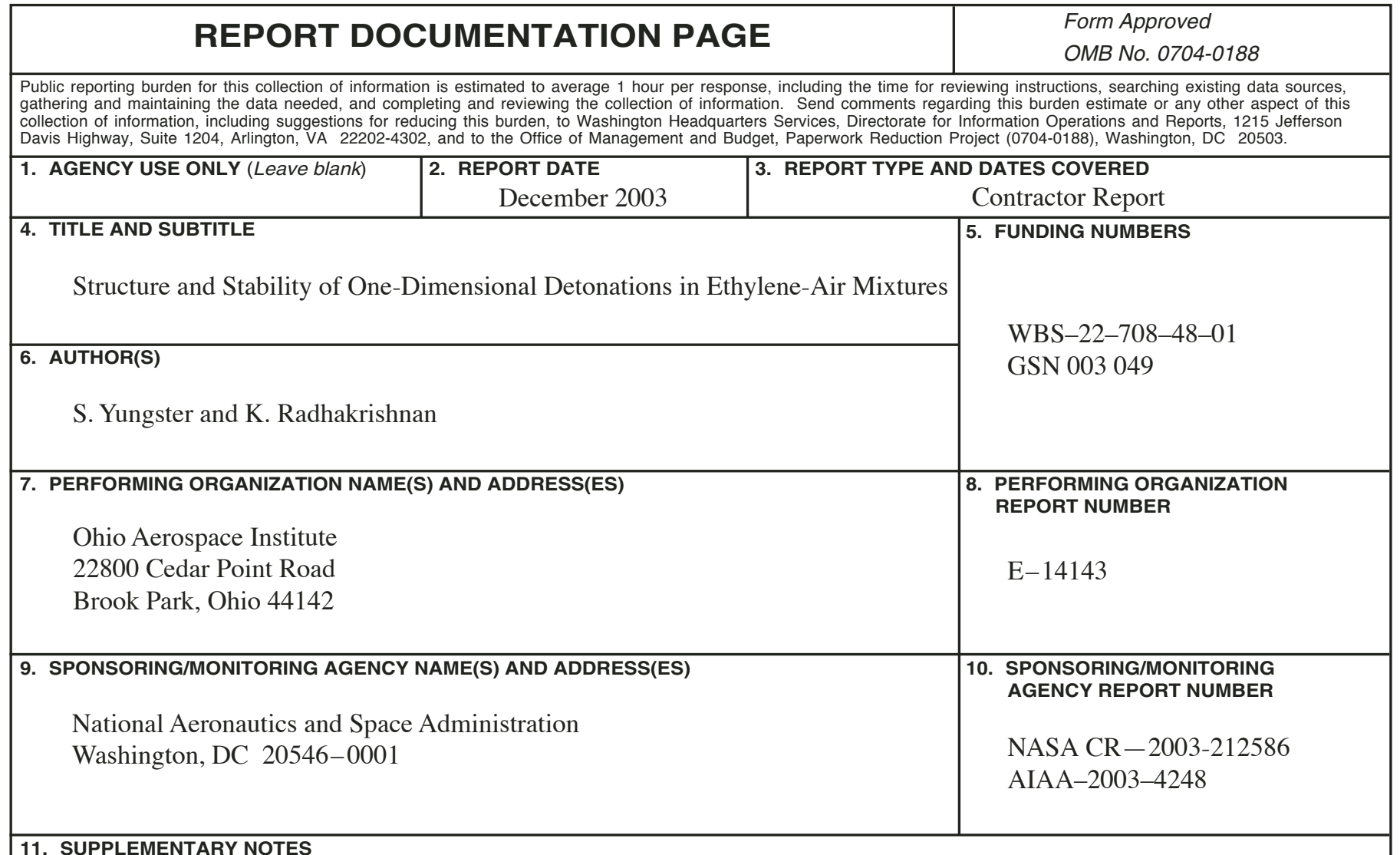

\section{SUPPLEMENTARY NOTES}

Prepared for the 33rd Fluid Dynamics Conference and Exhibit sponsored by the American Institute of Aeronautics and Astronautics, Orlando, Florida, June 23-26, 2003. Project Manager, Hugh D. Perkins, Aeropropulsion Research Program Office, NASA Glenn Research Center, organization code 0142, 216-977-7414.

12a. DISTRIBUTION/AVAILABILITY STATEMENT

12b. DISTRIBUTION CODE

Unclassified - Unlimited

Subject Category: 34

Distribution: Nonstandard

Available electronically at http://gltrs.grc.nasa.gov

This publication is available from the NASA Center for AeroSpace Information, 301-621-0390.

13. ABSTRACT (Maximum 200 words)

The propagation of one-dimensional detonations in ethylene-air mixtures is investigated numerically by solving the one-dimensional Euler equations with detailed finite-rate chemistry. The numerical method is based on a second-order spatially accurate total-variation-diminishing scheme and a point implicit, first-order-accurate, time marching algorithm. The ethylene-air combustion is modeled with a 20 -species, 36-step reaction mechanism. A multi-level, dynamically adaptive grid is utilized, in order to resolve the structure of the detonation. Parametric studies over an equivalence ratio range of $0.5<\phi<3$ for different initial pressures and degrees of detonation overdrive demonstrate that the detonation is unstable for low degrees of overdrive, but the dynamics of wave propagation varies with fuel-air equivalence ratio. For equivalence ratios less than approximately 1.2 the detonation exhibits a short-period oscillatory mode, characterized by high-frequency, low-amplitude waves. Richer mixtures $(\phi>1.2)$ exhibit a low-frequency mode that includes large fluctuations in the detonation wave speed; that is, a 'galloping' propagation mode is established. At high degrees of overdrive, stable detonation wave propagation is obtained. A modified McVey-Toong short-period wave-interaction theory is in excellent agreement with the numerical simulations.

\begin{tabular}{|c|c|c|c|}
\hline 14. SUBJECT TERMS & & & $\begin{array}{c}\text { 15. NUMBER OF PAGES } \\
20\end{array}$ \\
\hline N 7540-01 & & & $\begin{array}{l}\text { ndard Form } 298 \text { (Rev. 2-89) } \\
\text { cribed by ANSI Std. Z39-18 } \\
102\end{array}$ \\
\hline
\end{tabular}

